\title{
Pentraxin 3: an immuno-regulator in the lungs
}

\author{
1 Department of Immunology, University of Manitoba, Winnipeg, MB, Canada \\ 2 University Saint Boniface, Winnipeg, MB, Canada \\ ${ }^{3}$ Xinqiao Hospital, Third Military Medical University, Chongqing, China
}

Jyoti Balhara ${ }^{1}$, Latifa Koussih ${ }^{1,2}$, Jingbo Zhang $^{1,3}$ and Abdelilah Soussi Gounni ${ }^{1}{ }^{*}$

\section{Edited by:}

Anna Rubartelli, IRCCS AOU San

Martino IST, Italy

Reviewed by:

Cecilia Garlanda, Istituto Clinico

Humanitas, Italy

Darryl Knight, University of

Newcastle, Australia

*Correspondence:

Abdelilah Soussi Gounni, Department of Immunology, Faculty of Medicine, University of Manitoba, 419 Apotex

Centre, 750 McDermot Avenue,

Winnipeg, MB R3EOT5, Canada

e-mail:gounni@cc.umanitoba.ca
Pentraxin 3 (PTX3) is a soluble pattern recognition receptor that is a humoral component of the innate immune system. It interacts with pathogenic moieties, infected and dying host cells and facilitates their removal through activation of appropriate innate and adaptive mechanisms. PTX3 is secreted by a diverse variety of cells, ranging from immune cells to structural cells, in response to Toll like receptor (TLR) engagement, inflammatory stimuli, and physical and chemical stress. Further, PTX3 plays an essential role in female fertility as it facilitates the organization of extracellular matrix in the cumulus oophorus. Such activity is also implicated in post-inflammation tissue repair. PTX3 is a multifunctional protein and plays a non-redundant role in providing immunity against potential immunological dangers. Thus, we assessed its role in lung immunity, as lungs are at a constant risk of infections and tissue damage that is attributable to perpetual exposure to foreign agents.

Keywords: PTX3, TNF, IL-1 $\beta$, immune system, complements, lungs

\section{INTRODUCTION}

Pentraxins are a superfamily of evolutionarily conserved, specific pattern recognition proteins that play a salient role in the innate immune system. Based on size, these multifunctional proteins are divided into long and short pentraxins. Long pentraxins include the prototypic pentraxin 3 (PTX3), the recently identified PTX4, and neuronal pentraxins 1 (NP1) and NP2 whereas short pentraxins consist of $\mathrm{C}$-reactive protein $(\mathrm{CRP})$ and serum amyloid $\mathrm{P}$ (SAP) (Gewurz et al., 1995; Garlanda et al., 2005).

Phylogenetic analysis has demonstrated conservation of short and long pentraxins in human, mouse, rat, opossum, chicken, and some lower vertebrates (Martinez de la Torre et al., 2010). Although all pentraxins evolve from a common ancestor, PTX3 alone forms a separate cluster and seems to originate directly from the common ancestral pentraxin very early in evolution (Martinez de la Torre et al., 2010).

Pentraxin 3 has been identified as biomarker of several immunopathological states and its relevance with the resolution of infections and diseases has also been studied. In this review, we detail the general structure, expression, and functions of PTX3. Also discussed are current findings, which suggest an important role of PTX3 in immunological states, particularly those that are associated with the lungs.

\section{PTX3 GENE STRUCTURE}

The human and murine PTX3 gene is localized on chromosome 3 (q22-28) (Breviario et al., 1992). The PTX3 gene is organized into three exons: the first and the second exons translate to the leader peptide and $\mathrm{N}$-terminal domain, respectively, whereas the third exon which corresponds to second exon of short pentraxins, encodes pentraxin domain (Breviario et al., 1992) (Figure 1). The human and mouse PTX3 displays 92\% amino acid conservation and $82 \%$ of these amino acid residues are identical (Introna et al., 1996; Garlanda et al., 2005). Significant homology between human and mouse PTX3 suggests that murine studies can be extrapolated to address human issues.

The human PTX3 promoter contains several potential cis acting elements including an NF-kB site, binding sites for activator protein 1 (AP-1), AP-2, specificity protein (Sp1), and gamma interferon activation site (GAS) (Altmeyer et al., 1995) (Figure 1). In addition to these elements, the murine PTX3 gene promoter sequence also contains binding sites for homeodomain (Hox)1.3, and transcription factors belonging to Ets family. The mouse PTX3 gene contains a 44-bp stretch of alternating CA residues in its promoter region, which acts as an enhancer element. The murine promoter region also contains multiple NF-IL-6 binding sites while its human counterpart contain only one, which draws particular attention on the role of NF-IL-6 in the regulation of PTX3 expression (Darnell et al., 1994).

Unlike short pentraxins, the PTX3 promoter does not contain a consensus site for hepatic nuclear factor-1 (HNF-1), which accounts for the absence of its induction in liver (Darnell et al., 1994). Although human and murine PTX3 protein is homologous, the human promoter contains lesser transcriptional elements than does the murine promoter, an effect that needs to be studied using molecular and phylogenetic analysis.

\section{PTX3 PROTEIN STRUCTURE}

The name pentraxin is derived from the molecule's pentagonal structure, which consists of five subunits. It was initially thought that PTX3 acquired a quaternary structure that is similar to short pentraxins, which consists of five identical $23 \mathrm{kDa}$ subunits held together by noncovalent non-covalent interactions. However, the amino acid residues at the protomer interface that are required for pentameric structural formation in CRP, are not present in PTX3 (Introna et al., 1996). PTX3, exists mainly as octamers made from two tetramers and each subunit is held together by covalent bonds (Bottazzi et al., 1997; Garlanda et al., 2002; 


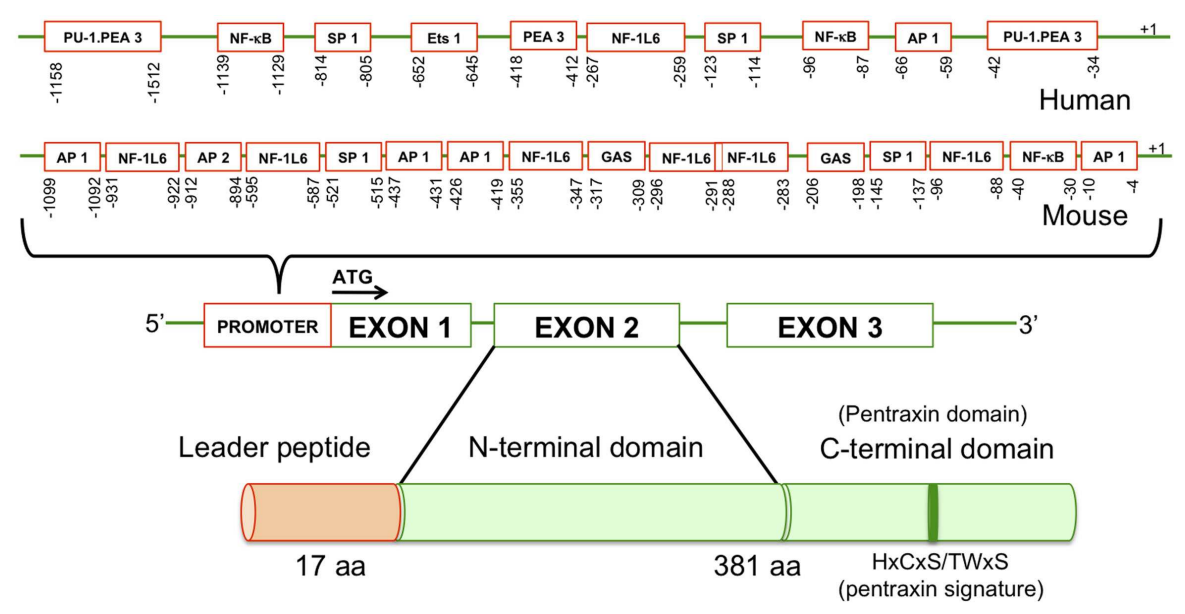

FIGURE 1 | Molecular structure of PTX3 gene in human and

mouse. PTX3 gene is organized into promoter region and three exons: the first exon encodes for leader peptide (17 amino acids) while the second and the third exons encode for $\mathrm{N}$ - and C-terminal domains of the protein (381 amino acids). Promoter region contains multiple transcription binding sites.
Inforzato et al., 2008). PTX3 octamers show greater functional activity as compared to tetrameric oligomers (Inforzato et al., 2008).

The PTX3 protein structure, like that of other pentraxins includes a pentraxin domain containing $\mathrm{HxCxS} / \mathrm{TWxS}$ (where $\mathrm{x}$ is any amino acid) at $\mathrm{C}$ terminus (Figure 1). Its C-terminal domain consists of 203 amino acids, 57\% of which are conserved in the entire pentraxin superfamily and the unique N-terminal domain consists of 178 amino acids (Agrawal et al., 2009). The PTX3 C- and N-terminal domains evolved independently, which explains why the C-terminal domain is widely conserved while the N-terminal domain is not (Martinez de la Torre et al., 2010). Mature PTX3 protein is approximately $40 \mathrm{kDa}$, but glycosylation at Asn220 increases the molecular weight to $45 \mathrm{kDa}$ (Garlanda et al., 2005). Oligosaccharide moieties at Asn220 can be complex or heterogenous sialic and fucosyl sugar moieties. Unique glycosylation patterns are associated with different inflammatory cells and inflammatory stimuli that induce PTX3 production (Inforzato et al., 2006). Desialylation of PTX3 results in stronger binding to $\mathrm{Clq}$ and activates the classical complement pathway to a sizable extent (Inforzato et al., 2006) (Table 1). The PTX3 protein has two conserved cysteine residues at the C-terminus (Cys210 and Cys271) and seven other cysteine residues, which are exclusive to PTX3: three at the N-terminus (Cys47, 49, and 103) and four in the C-terminal region (Cys179, 317, 318, and 357). These cysteine residues form a network of disulfide bonds that maintains the PTX3 oligomeric structure. Interchain Cys47-Cys47 and Cys49-Cys49 bonds form dimers and these dimers are further held together by Cys103-Cys103 bonds that maintain tetrameric structures (Doni et al., 2006). These tetrameric structures are further assembled into octamers by disulfide bonds between Cys317 and Cys318, which are located on exposed loops of different protomers (Inforzato et al., 2008). The PTX3 C-terminal domain is formed by two antiparallel $\beta$ sheets, stabilized by Cys 210 and 271 and organized into a $\beta$-jelly roll topology (Pepys and Baltz,
1983; Goodman et al., 1996). Cys179 and 357 also form disulfide bonds and seem to limit the flexibility of the $\mathrm{N}$ - and C-terminal regions by linking them together (Inforzato et al., 2008). The $\mathrm{N}$-terminal region, however, is predicted to assume a coiled coil conformation as it is made up of four alpha helices (Presta et al., 2007).

Recently, Delneste and coworkers showed that the PTX3 $\mathrm{N}$-terminal domain is susceptible to cleavage by proteases, particularly neutrophil elastase and Aspergillus fumigatus proteases (Hamon et al., 2013). The serine protease inhibitor PMSF, antipain, and chymostatin were shown to inhibit $A$. fumigatus proteases activity but its activity was unaffected by aspartic-, metallo-, cysteine-, and aminopeptidase protease inhibitors (Hamon et al., 2013). Proteolytic cleavage of PTX3 has added an interesting aspect to the regulation of PTX3 expression and function and a detailed analysis is necessary to validate this phenomenon.

\section{CELLULAR SOURCES OF PTX3}

There is a growing body of evidence suggesting that PTX3 can be produced by many cell types and induced by various different stimuli (Breviario et al., 1992; Lee et al., 1993). It is due to this reason that PTX3 is capable to serve multiple functions depending upon condition. It is interesting to note that regardless of the source of its production (immune cells or structural cells), PTX3 plays a critical role in regulation of the humoral arm of innate immunity (Lee et al., 1993).

\section{IMMUNE CELLS}

Lymphoid cells such as T cells, B cells, and NK cells do not express PTX3. This highlights the significance of PTX3's control on the innate immune system (Deban et al., 2011). However, the action of PTX3 is not limited to the innate immune system: PTX3 coordinates with adaptive immune system and facilitates protection against infections. 
Table 1 | Pentraxin 3 interacts with various ligands to mediate diverse function.

\begin{tabular}{|c|c|c|c|c|}
\hline & Ligand & Role & Characteristics of interaction & Reference \\
\hline 1 & P-selectin & Inhibition of neutrophil migration & $\begin{array}{l}\text { C-terminal domain is required } \\
\text { Dependent on glycosylation pattern }\end{array}$ & Deban et al. (2010) \\
\hline 2 & C1q & Complement activation & $\begin{array}{l}\text { C-terminal domain of PTX3 is required } \\
\text { Desialylation of PTX3 favors interaction } \\
\text { Interaction is mediated through globular } \\
\text { head of } \mathrm{C} 1 \mathrm{q} \\
\text { Inhibitory effect when } \mathrm{C} 1 \mathrm{q} \text { is in fluid } \\
\text { phase } \\
\text { Calcium independent }\end{array}$ & $\begin{array}{l}\text { Inforzato et al. (2006), Baruah et al. } \\
\text { (2006) }\end{array}$ \\
\hline 3 & Ficolins & Complement activation & $\begin{array}{l}\text { Calcium dependent } \\
\text { Interaction mediates through } \\
\text { fibrinogen-like domain of ficolins } \\
\text { Glycosylation pattern in C-terminal domain } \\
\text { of PTX3 is a determining factor }\end{array}$ & Ma et al. (2009), Gout et al. (2011) \\
\hline 4 & Factor $\mathrm{H}$ & Complement activation & $\begin{array}{l}\mathrm{N} \text { - and C-terminal domains are required } \\
\text { for interaction } \\
\text { Interaction is calcium dependent } \\
\text { Glycosylation of PTX3 stabilizes the } \\
\text { interaction }\end{array}$ & Deban et al. (2008) \\
\hline 5 & MBL & Complement activation & $\begin{array}{l}\text { Mediated through collagen like domain of } \\
\mathrm{MBL} \\
\text { Interaction dependent on calcium }\end{array}$ & Martin et al. (2009) \\
\hline 6 & FyRs & Opsonophagocytosis & & Moalli et al. (2010), Lu et al. (2008) \\
\hline 7 & $\mathrm{FGF}-2 / 8 \mathrm{~b}$ & Anti-angiogenesis & $\begin{array}{l}\text { Interaction through N-terminal domain } \\
\text { (FGF-2) }\end{array}$ & $\begin{array}{l}\text { Moalli et al. (2010), Lu et al. (2008), } \\
\text { Rusnati et al. (2004), Camozzi et al. } \\
(2005,2006)\end{array}$ \\
\hline 8 & TSG-6 & Extracellular matrix deposition & Interaction through $\mathrm{N}$-terminal domain & $\begin{array}{l}\text { Salustri et al. (2004), Maina et al. } \\
\text { (2009) }\end{array}$ \\
\hline 9 & $\begin{array}{l}\text { Galactomannan } \\
\text { (component of conidia) }\end{array}$ & Disposal of conidia & & Garlanda et al. (2002) \\
\hline 10 & $\begin{array}{l}\text { OmpA (Klebsiella } \\
\text { pneumoniae) }\end{array}$ & $\begin{array}{l}\text { Activation of immune response against } \\
\text { Klebsiella (complement activation) }\end{array}$ & $\begin{array}{l}\text { High affinity interaction } \\
\text { Calcium dependent }\end{array}$ & $\begin{array}{l}\text { Cotena et al. (2007), Jeannin et al. } \\
\text { (2005) }\end{array}$ \\
\hline 11 & Hemagglutinin & $\begin{array}{l}\text { Inhibition of viral attachment to host } \\
\text { cells }\end{array}$ & $\begin{array}{l}\text { Calcium independent } \\
\text { Sialic moiety on PTX3 and mannose on } \\
\text { hemagglutinin are involved in interaction }\end{array}$ & $\begin{array}{l}\text { Bozza et al. (2006), Reading et al. } \\
\text { (2008) }\end{array}$ \\
\hline
\end{tabular}

This table shows list of PTX3 ligands and role and characteristic features of their interaction.

\section{Dendritic cells}

Among cells of immune system, myeloid cells, and especially dendritic cells (DCs), are the main source of PTX3 (Introna et al., 1996). An intricate network, as demonstrated by Doni et al. (2006) regulates its expression in myeloid DCs upon stimulation with the Toll like receptor (TLR) ligands, CD40L, IL-10, and IL-1 $\beta$. However, no such effect was observed in plasmacytoid DCs. Macrophages also express PTX3. Macrophages from PTX3 overexpressing mice show an augmented phagocytic response to zymosan and Paracoccidioides brasiliensis (Deban et al., 2011).

\section{Neutrophils}

Neutrophils are the only granular cells reported to release preformed PTX3 in response to TLR agonists and microorganisms. PTX3 exists as a monomer in "ready to release" myeloperoxidase (MPO) negative granules containing lactoferrin and lactoferrin/gelatinase and assembles into multimers upon release. When neutrophils are activated in response to inflammatory stimulation, they release $25 \%$ of their PTX3. Part of the released PTX3 remains associated with neutrophil extracellular traps (NETs), which interacts with certain components of NETs (Jaillon et al., 2007; Daigo et al., 2012). Neutrophils are among the first cells to defend against foreign pathogens and the immediate 
release of PTX3 by these cells may be indicative of its importance in innate immunity.

\section{STRUCTURAL CELLS AND OTHER CELLS Adipocytes}

Pentraxin 3 is induced by TNF in adipocytes (AbderrahimFerkoune et al., 2003). Preadipocytes also showed PTX3 expression, which decreases upon differentiation to adipocytes. In light of differential PTX3 expression in different differentiation stages of adipocytes, function of PTX3 in this process was found irrelevant. Additionally, a greater level of PTX3 mRNA was observed in adipose tissue of obese and obese diabetic mice as compared to WT mice. Although authors suggested this expression resulted from adipocytes, examination of cell-specific PTX3 production in these tissues is requisite (Abderrahim-Ferkoune et al., 2003). Altogether, more studies are required to determine the functional outcome of the role of PTX3 during differentiation and also in obese condition.

\section{Cardiomyocytes}

Pentraxin 3 is constitutively expressed in the human heart by cardiomyocytes. (Peri et al., 2000). However dying and necrotic cells release it in large quantities, contributing to its increased level in the blood of patients with acute myocardial infarction (AMI) (Peri et al., 2000). Although its exact role in healthy myocytes is not well understood, it is generally used as an indicator of tissue damage in AMI (Peri et al., 2000). Heart myocytes experience constant physical stress. Whether such a stress is associated with PTX3 constitutive expression is not clear. PTX3 protein expression was shown to be increased in murine cardiomyocytes after transverse aortic constriction and $\mathrm{H}_{2} \mathrm{O}_{2}$ (Suzuki et al., 2003).

\section{Endothelial cells}

In atherosclerosis, high-density lipoprotein (HDL) induces the expression of PTX3 by activating a PI3K/Akt-dependent pathway in endothelial cells. Here PTX3 is suggested to manifest an antiinflammatory and protective function (Norata et al., 2008). PTX3 is also induced by Lysophosphatidic acid (LPA), the lipid component of oxidized low-density lipoproteins (oxLDL) through the activation of NF-kB and is suggested to have a proatherogenic function (Gustin et al., 2008). These contradictory observations advocate the need of a unifying study to unveil the exact role of PTX3 in the development or resolution of atherosclerosis.

\section{Epithelial cells}

Alveolar epithelial cells (ECs) produce PTX3 upon mechanical stretch in vitro (Wu et al., 2009). LPS and TNF also induce production of PTX3 in ECs (Han et al., 2005). Human proximal renal tubular ECs constitutively express PTX3 mRNA, which is further upregulated by IL-1 $\beta$, TNF, IL-17, and CD40L. IL- 6 and IL-4 have no effect on PTX3 expression whereas GM-CSF was shown to diminish the effect of IL-1 $\beta$ (Nauta et al., 2005).

\section{Chondrocytes}

Enhanced expression of PTX3 was observed in synoviocytes and in synovial fluid from patients with rheumatoid arthritis (RA). IL-1 $\beta$ and oncostatin M (OSM) synergistically induce PTX3 expression in chondrocytes of the synovium (Barksby et al., 2006; Andreas et al., 2009) but whether or not PTX3 is involved in cartilage repair or degradation is largely unexplored. Expression of PTX3 in RA synoviocyte is however unaffected by TNF or IL- $1 \beta$ but is down regulated by TGF- $\beta$ and IFN gamma (Luchetti et al., 2000).

\section{Brain cells}

Although PTX3 and neuronal pentraxins belongs to the same family, expression of former is generally not observed in the brain. It is, however induced by inflammatory stimuli such as LPS, TNF, and IL-1 in granule cells, presumptive glial cells in the white matter (corpus callosum, fimbria), meningeal pia mater, and dentate gyrus hilus (Polentarutti et al., 2000; Ravizza et al., 2001).

\section{PTX3 IN LUNG DISEASES}

The level of circulating PTX3 is low in healthy human condition $(<2 \mathrm{ng} / \mathrm{ml})$, but a rapid increase is observed in inflammatory conditions starting from very early stages. Due to its precocious appearance in various clinical conditions, research has focused on investigating whether PTX3 can be used as an index of systemic inflammatory activation. Another major reason suggestive of its suitability as a marker of severity of diseases like tuberculosis particularly in parasite endemic regions is the fact that its plasma level is unaffected by helminthic infections. There are several studies described in following sections, which demonstrate association between different diseased states and higher levels of PTX3.

\section{Chronic obstructive pulmonary disorder}

Chronic obstructive pulmonary disorder (COPD) is characterized by an irreversible airflow limitation that is associated with an abnormal inflammatory response in the lungs. The status of PTX3 in COPD patients is controversial. According to Van Pottelberge et al. (2012), no difference was observed in the levels of PTX3 in serum, sputum, pulmonary arteries, and alveolar space of COPD patients compared to healthy donors. However they claimed reduction in PTX3 positivity in lung sections obtained from moderate and severe COPD patients as compared to mild patients and healthy subjects (Van Pottelberge et al., 2012). Delneste and coworkers showed an increase in PTX3 level in serum and sputum of COPD patients compared to healthy people (Hamon et al., 2013). However, further investigation is required to determine whether this discrepancy in observation is due to the proteolytic cleavage of PTX3 in subjects participating in the former study or to the subjects' demographic characteristics. Among various causative agents, cigarette smoke (CS) is a major cause of chronic COPD (Pauwels et al., 2010). Subacute and chronic exposure to CS augments PTX3 levels in the lung tissue of a murine COPD model, particularly in the pulmonary veins and venules. This upregulation was found to be dependent on the IL-1 pathway. Further, a critical role of PTX3 in the regulation of COPD-induced pulmonary inflammation, emphysema, and body weight changes was ruled out in this study because no significant difference was observed between CS exposed PTX3 knock-out (KO) and WT mice (Pauwels et al., 2010).

\section{Asthma}

Pentraxin 3 expression is also found to be associated with the pathology of asthma. In human biopsy samples collected from 
healthy and asthmatic subjects, our lab has found an enhanced expression of PTX3 in airway epithelium, infiltrating inflammatory cells, and airway smooth muscle bundles of asthmatic samples compared to their healthy counterparts. Interestingly, we did not observe any difference in PTX3 positivity between the lung sections from mild, moderate, and severe asthmatic. Studies examining the role of potential proteolytic cleavage of PTX3 would provide detailed insight into the regulation of PTX3 expression in asthma. We have also investigated the production of PTX3 in primary human airway smooth muscle cells (HASMCs) and ECs in vitro and found that HASMCs produce greater PTX3 as compared to ECs. Further, TNF and IL- $1 \beta$ were found to significantly upregulate its expression in HASMCs, but the effect of Th2, Th1, and Th17 cytokines was found to be negligible. PTX3 induces the production of eotaxin-1/CCL-11. Further, stimulation of HASMCs with PTX3 is found to inhibit fibroblast growth factor-2 (FGF-2) mediated migration (Zhang et al., 2012).

\section{Lung carcinoma}

Initially, PTX3 was suggested to be useful only as a marker of lung carcinoma based on studies performed on lung cancer cell lines (Planque et al., 2009) but more recent studies have determined that PTX3 could be used as a serum biomarker for the diagnosis and prognosis of lung carcinoma. Its suitability is overwhelming due to its ability to differentiate between cancer patients and noncancer patients who are at higher risk of developing lung cancer (Diamandis et al., 2011).

\section{Acute lung injury}

Acute lung injury (ALI) and Acute Respiratory Distress Syndrome (ARDS) ALI/ARDS is characterized by injury associated with activation of the innate immune system in lungs. PTX3 is widely accepted as a marker of ALI because it is found in patients diagnosed with ALI within $24 \mathrm{~h}$ (He et al., 2007) and is closely associated with the severity of the disease. Concurrent infiltration of neutrophils, enhanced nitric oxide production, augmented expression, and function of tissue factor (TF) in lungs was observed in this pathological state (Lee et al., 1990, 1993, 1994). Consequently, it was suggested that a high level of PTX3 activates the local innate immune system, which was thought to serve a protective role against insults to which the lung tissue is exposed. LPS-induced ALI was investigated in PTX3 KO mice and the authors found that PTX3 KO mice were more susceptible to tissue damage as a result to LPS exposure compared to wild type mice (Okutani et al., 2007). In addition, PTX3 knock-in mice were observed to be better protected from LPS-induced endotoxemia (Dias et al., 2001). In an ALI model, PTX3 levels and the disease severity were found to be regulated by TF and TF, in turn, is induced by PTX3 (Han et al., 2011). Additional detailing of mechanisms in PTX3 $\mathrm{KO}$ mice other than the involvement of TF, which rendered them susceptible to ALI would shed more light on the role of PTX3.

\section{PTX3 AND LUNG INFECTIONS}

\section{Pseudomonas aeruginosa infection}

Pseudomonas aeruginosa is one of the prominent bacteria colonizing the lungs and causing chronic lung infections observed in Cystic Fibrosis (CF) patients. In humans, the PTX3 level increases in the serum of CF patients compared to healthy subjects (Hamon et al., 2013). Colonization of $P$. aeruginosa in CF patients is found to be positively associated with two intronic SNPs (rs1840680 and rs2305619) and one exonic SNP (rs3816527) in the PTX3 gene (Chiarini et al., 2010). In mouse, protective role of PTX3 was observed, as PTX3 KO mice are more susceptible to $P$. aeruginosa infection. Recombinant PTX3 facilitates the clearance of this pathogen by promoting an appropriate immune response in the lungs of PTX3 KO mice. This effect was demonstrated to be dependent on C3 and Fc $\gamma$ and independent of C1q (Moalli et al., 2011). The mechanism by which this protective role is mediated through the complement system is described elsewhere in this review. Intraperitoneally administered PTX3 decreased the concentration of inflammatory mediators such as IL-1 $\beta \beta$, IL-17, CCL-2/MCP-1, CXCL1/KC, and CXCL2/MIP-2 in P. aeroginosa infected CF mice as compared to untreated CF mice. PTX 3 treatment also decreased the infiltration of neutrophils and increased the percentage of monocytes in bronchoalveolar lavage fluid (BALF) from CF mice. Improvement in vascular leakage was also observed in CF mice upon PTX3 treatment (Paroni et al., 2012).

\section{Aspergillosis}

Aspergillus fumigatus is an opportunistic pathogen mainly infecting immunodeficient patients. In Invasive Pulmonary Aspergillosis (IPA), conidia of A. fumigatus induce the PTX3 secretion in the lungs which in turn recognizes and binds to the galactomannan moieties on the conidia and facilitates its phagocytosis by macrophages (Garlanda et al., 2002). Association of PTX3 with $\mathrm{C} 3 \mathrm{~b}$ and the resulting activation of $\mathrm{C} 11 \mathrm{~b}$ through $\mathrm{Fc} \gamma \mathrm{R}$ are also involved in this process (Moalli et al., 2010). Additionally, PTX3 is also related to the amplification of the antifungal response by inducing the release of MCP-1/CCL-2 in mononuclear phagocytes thus promoting homing of monocytes to the lung tissue to aid in clearing the pathogen (Garlanda et al., 2002). PTX3 also activates the lectin complement pathway by binding to ficolinL-bound Aspergillus conidia in an attempt to clear the infection (Moalli et al., 2010). Another mode of pathogen clearance is by the activation of DCs and subsequent induction of a Th1 response (Garlanda et al., 2002). In PTX3 KO mice, susceptibility to IPA was associated with increased levels of IL-4 (a Th2 cytokine) and decreased amounts of IFN gamma and IL-2 (Th1 cytokine). Pulmonary A. fumigatus infection is a major concern in immunocompromised patients, particularly in bone marrow transplant patients and PTX3 allows a rapid recovery of myeloid and lymphoid cells into the lung tissue, which helps to accelerate the reconstitution of the patients' immunity (Gaziano et al., 2004). Since cytomegalovirus (CMV) infections can also result in such an immuno-compromised state, PTX3 can resolve super infection by $A$. fumigatus even in a CMV-infected state (Bozza et al., 2006).

Pentraxin 3 shows differential binding patterns. It does not bind with hyphae but rather it binds only with the A. fumigatus, A. flavus, and A. niger conidia. However, interaction between PTX3 and fungal strains other than these such as Candida albicans is not observed (Garlanda et al., 2002). Thus direct action on $C$. albicans is not possible, but PTX3 can resolve Candida infection through binding with mannose binding lectin (MBL) (Table 1) and the subsequent recruitment of $\mathrm{Clq}$ and activation of classical 
complement cascade (Ma et al., 2009). The precise mechanism of $C$. albicans clearance from the lungs by PTX3 requires further investigation.

\section{Tuberculosis}

Plasma level of PTX3 is found to be correlated with the clinical severity of tuberculosis and therefore is seen as an appropriate indicator of the disease stage (Azzurri et al., 2005). PTX3 level declines with the success of therapeutic treatment against tuberculosis but increases again when treatment fails. This is also suggestive of the suitability of PTX3 as a tool to follow up the efficacy of treatment (Azzurri et al., 2005). Analysis of lung samples from human subjects determined that exposure to BCG vaccine leads to an increase in level of PTX3 (Aranday Cortes et al., 2010). This suggests that expression of PTX3 could be a protective mechanism and is not just a marker of the diseased state. One mechanism to confer immuno-protection may be mediated by monocytes that are induced to express PTX3 by the mycobacterial component (Mycobacterial lipoarabinomannan, LAM) (Vouret-Craviari et al., 1997). In humans, susceptibility to Mycobacterium tuberculi is also found to be positively associated with two intronic SNPs (rs1840680 and rs2305619) in PTX3 gene (Olesen et al., 2007). However some unanswered questions require further investigation, particularly, the mechanism of action of PTX3 on monocytes and involvement of other cell types in this process. It would also be worthwhile to determine any additional role for PTX3 plays additional roles in context with tuberculosis and its associated outcomes in the lungs.

\section{Pneumonia}

Klebsiella pneumoniae causes acute pulmonary infection in immuno-compromised subjects and results in pneumonia. Like other bacterial infections, PTX3 levels are found to be associated with the disease progression. A study by Soares et al. (2006) and Dias et al. (2001) determined that in PTX3 transgenic mice, high inoculum of bacteria induces overt expression of PTX3, and culminates in greater lethality. Very high levels of PTX3 inhibit neutrophil influx in the lungs due to inhibition of P-selectin (Deban et al., 2010) and enhanced NO production and iNOS expression (Soares et al., 2006). As a result of this, production of TNF was found inhibited, resulting in greater bacteria count in lung tissue (Soares et al., 2006). Since TNF induces PTX3 expression, one explanation for reduced production of TNF in this infection model could be a feedback mechanism to regulate PTX3 levels and exacerbations that may result from its very high levels. However, when PTX3 transgenic mice were infected with a smaller inoculum, protective effects of PTX3 were conferred and was attributed to enhanced TNF production, increased neutrophil infiltration to lungs and decreased bacterial load in lungs and blood (Soares et al., 2006). It is quite possible that such a protective effect is initiated by a mechanism that involves PTX3 induction by [Outer membrane protein A (OmpA) of K. pneumoniae] through TLR2, which in turn binds OmpA (Table 1) and amplifies the activation of complement cascade and promotes the opsonophagocytosis of OmpA containing bacteria (Jeannin et al., 2005; Cotena et al., 2007). In humans, a positive correlation is observed between plasma levels of PTX3 and the severity of Community acquired pneumonia
(CAP) and that PTX3 concentration decreased upon treatment with antibiotics. The PTX3 level was also found to be significantly correlated with the length of the hospital stay for CAP patients (Kao et al., 2012).

\section{Cytomegalovirus infection}

Cytomegalovirus is a herpes virus, present in the majority of the general population. It exists in latent form even after the infection is treated and may reactivate in an immunocompromised state (Forbes, 1989). PTX3 not only provides protection at very early stages of CMV infection, but also suppresses reactivation (Bozza et al., 2006). PTX3 mediates its action by binding to hemagglutinin (Table 1) on the surface of the virus and blocks its entry into host cells, particularly DCs (Bozza et al., 2006). It can also induce antiviral immunity through the activation of mDCs and subsequent up regulation of appropriate $\mathrm{T}$ cells functions (Bozza et al., 2006). Virus-bound PTX3 acts through TLR2, 3, and 4 and induces the production of IFN gamma and IL-12 through the transcription factor IRF3 in CD11b ${ }^{+}$DCs C57BL/6 mice (Bozza et al., 2006). mDCs themselves also secrete PTX3 upon exposure to viral particles and maintains the loop of infection followed by immunoprotection. Exogenous PTX3 is a promising potential therapeutic agent against CMV infection, both alone (Bozza et al., 2006) and in combination with Thymosin alpha-1 (Patent: use of thymosin alpha-1, alone and in combination with PTX3 or Ganciclovir, for the treatment of cytomegalovirus infection).

\section{Influenza}

The Influenza virus presents another serious challenge to the respiratory tract because of its ability to mutate and create virulent variants as a mechanism to evade the host immune system. Influenza viruses are RNA orthomyxoviruses, which infect ECs of the respiratory tract (Matrosovich et al., 2004). A detailed study by Reading et al. (2008) showed that like CMV, a sialic moiety of PTX3 engages hemagglutinin of the influenza virus and hinders attachment of the virus to host ECs. Inhibition of viral neuraminidase glycoprotein by PTX3 could be an additional strategy to limit viral infection as it inhibits the release of newly formed viral particles from the infected host cells (Kilbourne et al., 1968). PTX3 also facilitates opsonization and clearance of infected cells. PTX3 KO mice are more prone to influenza virus infection but attained resistance when treated with exogenous PTX3 (Reading et al., 2008).

\section{Severe acute respiratory syndrome}

Severe Acute Respiratory Syndrome (SARS) is caused by SARS coronaviruses (SRAS-CoV) (Rota et al., 2003). The role of PTX3 is discussed with respect to murine hepatitis virus (MHV) which is a group 2 coronavirus that is closely related to its human counterpart SARS-CoV (Rota et al., 2003; Han et al., 2012). MHV-1 infection results in ALI in mice, similar to airways damage observed in the lungs of SARS patients (De Albuquerque et al., 2006). MHV-1 airway infection induces PTX3 expression in the lungs. PTX3 bound to MHV-1, reduced its infectivity and accelerated viral clearance. Consequently, PTX3 KO mice showed greater pulmonary damage as compared to their WT counterparts and the animals that were treated with exogenous PTX3. In PTX3 KO mice, an early influx 
of neutrophils and macrophages into the lungs is found to exaggerate lung injury due to $\mathrm{MHV}-1$ infection. Other inflammatory determinants such as IL-6, MCP-1, and MIP-1b were found to be enhanced in the PTX3 KO condition. However, production of these inflammatory cytokines was reduced upon PTX3 treatment, resulting in protection from airway damage (Han et al., 2012).

As a matter of caution, PTX3 is not a general mechanism to guard against all pathogenic infections. Infection due to Listeria monocytogenes and Salmonella typhimurium is neither controlled nor exaggerated by PTX3 directly or indirectly. Similarly, PTX3 is unable to bind and mediate protection against some variants of Influenza virus such as A/PR8/34 (HINI), H3N3, and type B influenza viruses (Reading et al., 2008).

\section{MECHANISM OF ACTION}

Pentraxin 3 exerts diverse functions to provide immunoprotection in multiple ways. It binds to the surface of pathogens and apoptotic inflammatory cells and promotes their opsonization and clearance early in the infection process. This role is important to avoid inducing a deleterious hyper-inflammatory state that could arise due to activation of the adaptive arm of the immune response. Notably, although the N-terminal domain of PTX3 is suggested to be required for pathogen binding, the fulllength protein is required for opsonizatio (Moalli et al., 2010). Also PTX3 when bound to pathogenic components activates DCs, which is instrumental in initiating an appropriate $\mathrm{T}$ cell response. Another mechanism by which PTX3 initiates the thread of innate immunity is by activating the complement cascade (Bozza et al., 2006).

\section{Complement pathway activation}

A prototypical paradigm by which PTX3 activates the classical complement pathway is by interacting with C1q (Table 1). PTX3 binds to the globular head of immobilized C1q through its Cterminal domain, subsequently triggering the activation of the downstream cascade. Glycosidic patterns on PTX3 significantly contribute to its interaction with Clq (Inforzato et al., 2006). Of note, when C1q is in solution, PTX3 inhibits the activation of complement pathway by blocking $\mathrm{Clq}$ interaction with immunoglobulins or other agents (Baruah et al., 2006).

Eventually, the ability of PTX3 to resolve Aspergillus infection in $\mathrm{C} 1 \mathrm{q} \mathrm{KO}$ mice but not in $\mathrm{C} 3 \mathrm{KO}$ mice indicated that PTX3 might also interact with other members of the complement family to mediate its function. PTX3 amplifies C3b-mediated opsonization and phagocytosis of Aspergillus conidia through inside-out activation of CD11b in macrophages (Moalli et al., 2010). Conidiabound PTX3 binds to Factor H (Table 1) and promotes C3mediated activation of the alternate pathway ( $\mathrm{C} 3$ is also deposited on conidia) and killing of the pathogen. A similar mechanism is employed to remove apoptotic cells which can be a potential cause of unwanted inflammation (Deban et al., 2008). Factor $\mathrm{H}$ binds to PTX3 at two sites: the PTX3 N-terminus acts as the primary binding site and the glycosylated pentraxins domain acts as the secondary binding site (Deban et al., 2008). While investigating the role of PTX3 in the disposal of Aspergillus conidia, Moalli et al. (2010) found that factor B of the alternate pathway is also necessary for its activity.
Pathogens attempt to evade the immune system so as to infect the host, in turn, activates multiple immune mechanisms to fight against the infection. The work of Moalli et al. (2010) implicated the role of all complement pathways in conidia opsonization. The association of PTX3 with other complement components further strengthens the suggestion. Along the same line, PTX3 was also found to activate the lectin complement pathway, by interacting with ficolins through their fibrinogen-like domain (Table 1) (Martin et al., 2009). Ficolins recognize carbohydrate moieties on pathogens and dying cells and provide immuno-protection by activating the lectin complement pathway and prime the adaptive immune response (Endo et al., 2011). Besides binding to ficolin-L, PTX3 enhances complement activation resulting from ficolinL interaction with Aspergillus (Ma et al., 2009, 2011). However the interaction between ficolin-L and PTX3 is critically affected by polymorphism in ficolin-L gene causing a T236 amino acid change in the fibrinogen-like domain (Ma et al., 2009). Similarly, ficolin-M also interfaces with PTX3 (Ma et al., 2009). This may be of even greater significance in this review because ficolin-M is majorly produced and found in the lungs (Ma et al., 2009; Gout et al., 2011). The ficolin-M tetramer binds to four PTX3 molecules where a sialic moiety in an N-linked carbohydrate of the C-terminal domain of later was found to be involved (Gout et al., 2011).

\section{PTX3 RECEPTOR AND LIGANDS}

Because PTX3 acts on immune cells, playing a critical role in driving innate immunity against pathogens, it is possible that PTX3 might act through some unknown receptor. A study investigating the binding properties of pentraxins with FcyRs determined that PTX3 could recognize FcyRs (Lu et al., 2008) (Table 1). The functional significance of such an interaction was later established in an Aspergillus infection model (Moalli et al., 2010). The protective effect of PTX3 against Aspergillus was found to be diminished in the absence of $\mathrm{Fc} \gamma \mathrm{R}$. This interaction was suggested to activate CD11b to induce opsonophagocytosis of the pathogen (Moalli et al., 2010). With the diverse functions mediated by PTX3 at the cellular level, it is likely that PTX3 may interact with additional unknown receptors, which could be the subject of further investigation.

Pentraxin 3 binds to FGF-2 (Rusnati et al., 2004; Camozzi et al., 2006) and fibroblast growth factor-8b (FGF-8b) (Leali et al., 2011) (Table 1) and affects neovascularization by mediating anti-angiogenic and anti-restenotic activity. FGF-2 induces proliferation in vascular smooth muscle cells and endothelial cells, which is inhibited by PTX3 (Rusnati et al., 2004; Camozzi et al., 2005). PTX3 inhibits FGF-2 functions by physically interacting through its N-terminal domain (Camozzi et al., 2006). TSG-6 also interacts with PTX3 through the same domain and as a result, it competes with FGF-2, thus abolishes the inhibitory effect of PTX3 on FGF-2-mediated angiogenesis (Leali et al., 2012). The association between TSG- 6 and PTX 3 is extremely critical in orchestrating ECM in cumulus oophorus, which is important for female fertility (Salustri et al., 2004). Thus because PTX3 and TSG-6 were found to be co-regulated in monocytes, macrophages and myeloid DCs, their association was suggested to contribute to ECM remodeling during inflammation (Maina et al., 2009). 


\section{CONCLUDING REMARIKS}

Pentraxin 3, a unique member of the long pentraxins family, plays an indispensable role in regulating our immune system against pathogens, which are involved in several pulmonary pathologies. Multiple mechanisms to recognize pathogens and to coordinate with the activation of humoral and cell-mediated immunity might explain why it is evolutionarily conserved from non-vertebrates to complex and highly evolved vertebrates. Several disease and

\section{REFERENCES}

Abderrahim-Ferkoune, A., Bezy, O., Chiellini, C., Maffei, M., Grimaldi, P., Bonino, F., et al. (2003). Characterization of the long pentraxin PTX3 as a TNFCE \pm induced secreted protein of adipose cells. J. Lipid Res. 44, 994-1000. doi:10.1194/jlr.M200382-JLR200

Agrawal, A., Singh, P. P., Bottazzi, B., Garlanda, C., and Mantovani, A. (2009). Pattern recognition by pentraxins. Adv. Exp. Med. Biol. 653, 98-116. doi:10.1007/9781-4419-0901-5_7

Altmeyer, A., Klampfer, L., Goodman, A. R., and Vilcek, J. (1995). Promoter structure and transcriptional activation of the murine TSG-14 gene encoding a tumor necrosis factor/interleukin-1-inducible pentraxin protein. J. Biol. Chem. 270, 25584-25590.

Andreas, K., Haupl, T., Lubke, C., Ringe, J., Morawietz, L., Wachtel, A., et al. (2009). Antirheumatic drug response signatures in human chondrocytes: potential molecular targets to stimulate cartilage regeneration. Arthritis Res. Ther. 11, R15. doi:10.1186/ar2605

Aranday Cortes, E., Kaveh, D., NunezGarcia, J., Hogarth, P. J., and Vordermeier, H. M. (2010). Mycobacterium bovis-BCG vaccination induces specific pulmonary transcriptome biosignatures in mice. PLoS ONE 5:e11319. doi:10.1371/journal.pone.0011319

Azzurri, A., Sow, O. Y., Amedei, A., Bah, B., Diallo, S., Peri, G., et al. (2005). IFN-gamma-inducible protein 10 and pentraxin 3 plasma levels are tools for monitoring inflammation and disease activity in Mycobacterium tuberculosis infection. Microbes Infect. 7, 1-8. doi:10.1016/j.micinf.2004.09.004

Barksby, H. E., Hui, W., Wappler, I., Peters, H. H., Milner, J. M., Richards, C. D., et al. (2006). Interleukin-1 in combination with oncostatin $\mathrm{M}$ up-regulates multiple genes in chondrocytes: implications for cartilage destruction and repair. Arthritis Rheum. 54, 540-550. doi:10.1002/art.21574
Baruah, P., Dumitriu, I. E., Peri, G., Russo, V., Mantovani, A., Manfredi, A. A., et al. (2006). The tissue pentraxin PTX3 limits Clq-mediated complement activation and phagocytosis of apoptotic cells by dendritic cells. J. Leukoc. Biol. 80, 87-95. doi:10.1189/jlb.0805445

Bottazzi, B., Vouret-Craviari, V., Bastone, A., De Gioia, L., Matteucci, C., Peri, G., et al. (1997). Multimer formation and ligand recognition by the long pentraxin PTX3. Similarities and differences with the short pentraxins $\mathrm{C}$-reactive protein and serum amyloid $\mathrm{P}$ component. J. Biol. Chem. 272, 32817-32823. doi:10.1074/jbc.272.52.32817

Bozza, S., Bistoni, F., Gaziano, R., Pitzurra, L., Zelante, T., Bonifazi, P., et al. (2006). Pentraxin 3 protects from MCMV infection and reactivation through TLR sensing pathways leading to IRF3 activation. Blood 108, 3387-3396. doi:10.1182/blood2006-03-009266

Breviario, F., d'Aniello, E. M., Golay, J., Peri, G., Bottazzi, B., Bairoch, A., et al. (1992). Interleukin-1inducible genes in endothelial cells. Cloning of a new gene related to C-reactive protein and serum amyloid P component. J. Biol. Chem. 267, 22190-22197.

Camozzi, M., Rusnati, M., Bugatti, A., Bottazzi, B., Mantovani, A., Bastone, A., et al. (2006). Identification of an antiangiogenic FGF2-binding site in the $\mathrm{N}$ terminus of the soluble pattern recognition receptor PTX3. J. Biol. Chem. 281, 22605-22613. doi:10.1074/jbc.M601023200

Camozzi, M., Zacchigna, S., Rusnati, M., Coltrini, D., Ramirez-Correa, G., Bottazzi, B., et al. (2005). Pentraxin 3 inhibits fibroblast growth factor 2-dependent activation of smooth muscle cells in vitro and neointima formation in vivo. Arterioscler. Thromb. Vasc. Biol. 25, 1837-1842. doi:10.1161/01.ATV.0000177807.54 959.7d

Chiarini, M., Sabelli, C., Melotti, P., Garlanda, C., Savoldi, G., Mazza, C., et al. (2010). PTX3 genetic variations affect the risk of Pseudomonas aeruginosa airway colonization in cystic

infection models have been extremely useful in understanding the role of PTX3 in normal and immuno-compromised disease states. However, detailed and comprehensive investigations unveiling the mechanisms by which PTX3 may modulate the immune system are certainly needed. PTX3 is an essential factor in determining female fertility, as it is instrumental in matrix deposition in cumulus oophorus. Characterization of its role in other physiological processes also requires further research.

fibrosis patients. Genes Immun. 11, 665-670. doi:10.1038/gene.2010.41

Cotena, A., Maina, V., Sironi, M., Bottazzi, B., Jeannin, P., Vecchi, A., et al. (2007). Complement dependent amplification of the innate response to a cognate microbial ligand by the long pentraxin PTX3. J. Immunol. 179, 6311-6317.

Daigo, K., Yamaguchi, N., Kawamura, T., Matsubara, K., Jiang, S., Ohashi, R., et al. (2012). The proteomic profile of circulating pentraxin 3 (PTX3) complex in sepsis demonstrates the interaction with azurocidin 1 and other components of neutrophil extracellular traps. Mol. Cell. Proteomics 11, M111015073. doi:10.1074/mcp.M111.015073

Darnell, J., Kerr, I., and Stark, G. (1994), Jak-STAT pathways and transcriptional activation in response to IFNs and other extracellular signaling proteins. Science 264, 1415-1421. doi:10.1126/science.8197455

De Albuquerque, N., Baig, E., Ma, X., Zhang, J., He, W., Rowe, A., et al. (2006). Murine hepatitis virus strain 1 produces a clinically relevant model of severe acute respiratory syndrome in $\mathrm{A} / \mathrm{J}$ mice. J. Virol. 80, 10382-10394. doi:10.1128/JVI.00747-06

Deban, L., Jaillon, S., Garlanda, C., Bottazzi, B., and Mantovani, A. (2011) Pentraxins in innate immunity: lessons from PTX3. Cell Tissue Res. 343, 237-249. doi:10.1007/s00441010-1018-0

Deban, L., Jarva, H., Lehtinen, M. J., Bottazzi, B., Bastone, A., Doni, A., et al. (2008). Binding of the long pentraxin PTX3 to factor $\mathrm{H}$ : interacting domains and function in the regulation of complement activation. $J$. Immunol. 181, 8433-8440.

Deban, L., Russo, R. C., Sironi, M., Moalli, F., Scanziani, M., Zambelli, V., et al. (2010). Regulation of leukocyte recruitment by the long pentraxin PTX3. Nat. Immunol. 11, 328-334. doi:10.1038/ni.1854

Diamandis, E. P., Goodglick, L., Planque, C., and Thornquist, M. D. (2011). Pentraxin-3 is a novel biomarker of lung carcinoma. Clin. Cancer Res. 17, 2395-2399.

\section{doi:10.1158/1078-0432.CCR-10-} 3024

Dias, A. A., Goodman, A. R., Dos Santos, J. L., Gomes, R. N., Altmeyer, A., Bozza, P. T., et al. (2001). TSG14 transgenic mice have improved survival to endotoxemia and to CLPinduced sepsis. J. Leukoc. Biol. 69, 928-936.

Doni, A., Michela, M., Bottazzi, B., Peri, G., Valentino, S., Polentarutti, N., et al. (2006). Regulation of PTX3, a key component of humoral innate immunity in human dendritic cells: stimulation by IL- 10 and inhibition by IFN-gamma. J. Leukoc. Biol. 79, 797-802. doi:10.1189/jlb. 0905493

Endo, Y., Matsushita, M., and Fujita, T. (2011). The role of ficolins in the lectin pathway of innate immunity. Int. J. Biochem. Cell Biol. 43, 705-712. doi:10.1016/j.biocel.2011.02.003

Forbes, B. A. (1989). Acquisition of cytomegalovirus infection: an update. Clin. Microbiol. Rev. 2 204-216.

Garlanda, C., Bottazzi, B., Bastone, A., and Mantovani, A. (2005). Pentraxins at the crossroads between innate immunity, inflammation, matrix deposition, and female fertility. Annu. Rev. Immunol. 23, 337-366. doi:10.1146/annurev.immunol.23.02 1704.115756

Garlanda, C., Hirsch, E., Bozza, S., Salustri, A., De Acetis, M., Nota, R., et al. (2002). Non-redundant role of the long pentraxin PTX3 in anti-fungal innate immune response. Nature 420, 182-186. doi:10.1038/nature01195

Gaziano, R., Bozza, S., Bellocchio, S., Perruccio, K., Montagnoli, C., Pitzurra, L., et al. (2004). AntiAspergillus fumigatus efficacy of pentraxin 3 alone and in combination with antifungals. Antimicrob. Agents Chemother. 48, 4414-4421. doi:10.1128/AAC.48.11.44144421.2004

Gewurz, H., Zhang, X. H., and Lint, T. F. (1995). Structure and function of the pentraxins. Curr. Opin. Immunol. 7, 54-64. doi:10.1016/0952-7915(95)80029-8 
Goodman, A. R., Cardozo, T., Abagyan, R., Altmeyer, A., Wisniewski, H. G., and Vilcek, J. (1996). Long pentraxins: an emerging group of proteins with diverse functions. Cytokine Growth Factor Rev. 7, 191-202. doi:10.1016/1359-6101(96)00019-6

Gout, E., Moriscot, C., Doni, A., Dumestre-Perard, C., Lacroix, M., Perard, J., et al. (2011). Mficolin interacts with the long pentraxin PTX3: a novel case of cross-talk between soluble pattern-recognition molecules. J. Immunol. 186, 5815-5822. doi:10.4049/jimmunol.1100180

Gustin, C., Delaive, E., Dieu, M., Calay, D., and Raes, M. (2008). Upregulation of pentraxin-3 in human endothelial cells after lysophosphatidic acid exposure. Arterioscler. Thromb. Vasc. Biol. 28, 491-497. doi:10.1161/ATVBAHA.107.158642

Hamon, Y., Jaillon, S., Person, C., Ginies, J. L., Garo, E., Bottazzi, B., et al. (2013). Proteolytic cleavage of the long pentraxin PTX3 in the airways of cystic fibrosis patients. Innate Immun. doi:10.1177/1753425913476741

Han, B., Haitsma, J. J., Zhang, Y., Bai, X., Rubacha, M., Keshavjee, S., et al. (2011). Long pentraxin PTX3 deficiency worsens LPS-induced acute lung injury. Intensive Care Med. 37, 334-342. doi:10.1007/s00134010-2067-2

Han, B., Ma, X., Zhang, J., Zhang, Y., Bai, X., Hwang, D. M., et al. (2012). Protective effects of long pentraxin PTX3 on lung injury in a severe acute respiratory syndrome model in mice. Lab. Invest. 92, 1285-1296. doi:10.1038/labinvest.2012.92

Han, B., Mura, M., Andrade, C. F., Okutani, D., Lodyga, M., dos Santos, C. C., et al. (2005). TNFalpha-induced long pentraxin PTX3 expression in human lung epithelial cells via JNK. J. Immunol. 175, 8303-8311.

He, X., Han, B., and Liu, M. (2007). Long pentraxin 3 in pulmonary infection and acute lung injury. Am. J. Physiol. Lung Cell. Mol. Physiol. 292, L1039-L1049. doi:10.1152/ajplung.00490.2006

Inforzato, A., Peri, G., Doni, A., Garlanda, C., Mantovani, A., Bastone, A., et al. (2006). Structure and function of the long pentraxin PTX3 glycosidic moiety: fine-tuning of the interaction with $\mathrm{Clq}$ and complement activation. Biochemistry 45, 11540-11551. doi:10.1021/bi0607453

Inforzato, A., Rivieccio, V., Morreale, A. P., Bastone, A., Salustri, A., Scarchilli, L., et al. (2008).
Structural characterization of PTX3 disulfide bond network and its multimeric status in cumulus matrix organization. J. Biol. Chem. 283, 10147-10161. doi:10.1074/jbc.M708535200

Introna, M., Alles, V. V., Castellano, M., Picardi, G., De Gioia, L., Bottazzai, B., et al. (1996). Cloning of mouse ptx3, a new member of the pentraxin gene family expressed at extrahepatic sites. Blood 87, 1862-1872.

Jaillon, S. B., Peri, G., Delneste, Y., Frémaux, I., Doni, A., Moalli, F., et al. (2007). The humoral pattern recognition receptor PTX3 is stored in neutrophil granules and localizes in extracellular traps. J. Exp. Med. 204, 793-804. doi:10.1084/jem.20061301

Jeannin, P., Bottazzi, B., Sironi, M., Doni, A., Rusnati, M., Presta, M., et al. (2005). Complexity and complementarity of outer membrane protein A recognition by cellular and humoral innate immunity receptors. Immunity 22, 551-560. doi:10.1016/j.immuni.2005.03.008

Kao, S. J., Yang, H. W., Tsao, S. M., Cheng, C. W., Bien, M. Y., Yu, M. C., et al. (2012). Plasma long pentraxin 3 (PTX3) concentration is a novel marker of disease activity in patients with community-acquired pneumonia. Clin. Chem. Lab. Med. 51, 1-7. doi:10.1515/cclm-2012-0459

Kilbourne, E. D., Laver, W. G., Schulman, J. L., and Webster, R. G. (1968). Antiviral activity of antiserum specific for an influenza virus neuraminidase. J. Virol. 2, 281-288.

Leali, D., Alessi, P., Coltrini, D., Ronca, R., Corsini, M., Nardo, G., et al. (2011). Long pentraxin-3 inhibits FGF8b-dependent angiogenesis and growth of steroid hormoneregulated tumors. Mol. Cancer Ther. 10, 1600-1610. doi:10.1158/15357163.MCT-11-0286

Leali, D., Inforzato, A., Ronca, R., Bianchi, R., Belleri, M., Coltrini, D., et al. (2012). Long pentraxin 3/tumor necrosis factor-stimulated gene- 6 interaction: a biological rheostat for fibroblast growth factor 2mediated angiogenesis. Arterioscler. Thromb. Vasc. Biol. 32, 696-703. doi:10.1161/ATVBAHA.111.243998

Lee, G., Lee, T., and Vilcek, J. (1993). TSG-14, a tumor necrosis factorand IL-1-inducible protein, is a novel member of the pentaxin family of acute phase proteins. J. Immunol. 150, 1804-1812.

Lee, G. W., Goodman, A. R., Lee, T. H., and Vilcek, J. (1994). Relationship of TSG-14 protein to the pentraxin family of major acute phase proteins. J. Immunol. 153, 3700-3707.

Lee, T. H., Lee, G. W., Ziff, E. B., and Vilcek, J. (1990). Isolation and characterization of eight tumor necrosis factor-induced gene sequences from human fibroblasts. Mol. Cell. Biol. 10, 1982-1988.

Lu, J., Marnell, L. L., Marjon, K. D., Mold, C., Du Clos, T. W., and Sun, P. D. (2008). Structural recognition and functional activation of FcgammaR by innate pentraxins. Nature 456, 989-992. doi:10.1038/nature07468

Luchetti, M. M., Piccinini, G., Mantovani, A., Peri, G., Matteucci, C., Pomponio, G., et al. (2000). Expression and production of the long pentraxin PTX3 in rheumatoid arthritis (RA). Clin. Exp. Immunol. 119, 196-202.

Ma, Y. J., Doni, A., Hummelshoj, T., Honore, C., Bastone, A., Mantovani, A., et al. (2009). Synergy between ficolin-2 and pentraxin 3 boosts innate immune recognition and complement deposition. J. Biol. Chem. 284, 28263-28275. doi:10.1074/jbc.M109.009225

Ma, Y. J., Doni, A., Skjoedt, M. O. Honore, C., Arendrup, M., Mantovani, A., et al. (2011). Heterocomplexes of mannose-binding lectin and the pentraxins PTX3 or serum amyloid P component trigger crossactivation of the complement system. J. Biol. Chem. 286, 3405-3417. doi:10.1074/jbc.M110.190637

Maina, V., Cotena, A., Doni, A., Nebuloni, M., Pasqualini, F., Milner, C. M., et al. (2009). Coregulation in human leukocytes of the long pentraxin PTX3 and TSG-6. J. Leukoc. Biol. 86, 123-132. doi:10.1189/jlb.0608345

Martin, B., Hirota, K., Cua, D. J., Stockinger, B., and Veldhoen, M. (2009). Interleukin-17-producing gammadelta $\mathrm{T}$ cells selectively expand in response to pathogen products and environmental signals. Immunity 31, 321-330. doi:10.1016/j.immuni.2009.06.020

Martinez de la Torre, Y., Fabbri, M., Jaillon, S., Bastone, A., Nebuloni, M., Vecchi, A., et al. (2010). Evolution of the pentraxin family: the new entry PTX4. J. Immunol. 184, 5055-5064. doi:10.4049/jimmunol.0901672

Matrosovich, M. N., Matrosovich, T. Y., Gray, T., Roberts, N. A., and Klenk, H. D. (2004). Human and avian influenza viruses target different cell types in cultures of human airway epithelium. Proc. Natl. Acad. Sci. U.S.A. 101, 4620-4624. doi:10.1073/pnas.0308001101
Moalli, F., Doni, A., Deban, L., Zelante, T., Zagarella, S., Bottazzi, B., et al. (2010). Role of complement and Fc $\{$ gamma $\}$ receptors in the protective activity of the long pentraxin PTX3 against Aspergillus fumigatus. Blood 116, 5170-5180. doi:10.1182/blood-2009-12-258376

Moalli, F., Paroni, M., Veliz Rodriguez, T., Riva, F., Polentarutti, N., Bottazzi, B., et al. (2011). The therapeutic potential of the humoral pattern recognition molecule PTX3 in chronic lung infection caused by Pseudomonas aeruginosa. J. Immunol. 186, 5425-5434.

Nauta, A. J., de Haij, S., Bottazzi, B., Mantovani, A., Borrias, M. C., Aten, J., et al. (2005). Human renal epithelial cells produce the long pentraxin PTX3. Kidney Int 67, 543-553. doi:10.1111/j.15231755.2005.67111.x

Norata, G. D., Marchesi, P., Pirillo, A., Uboldi, P., Chiesa, G., Maina, V., et al. (2008). Long pentraxin 3, a key component of innate immunity, is modulated by high-density lipoproteins in endothelial cells. Arterioscler. Thromb. Vasc. Biol. 28, 925-931. doi:10.1161/ATVBAHA.107.160606

Okutani, D., Han, B., Mura, M., Waddell, T. K., Keshavjee, S., and Liu, M. (2007). High-volume ventilation induces pentraxin 3 expression in multiple acute lung injury models in rats. Am. J. Physiol. Lung Cell. Mol. Physiol. 292, L144-L153. doi:10.1152/ajplung.00002.2006

Olesen, R., Wejse, C., Velez, D. R., Bisseye, C., Sodemann, M., Aaby, P., et al. (2007). DC-SIGN (CD209), pentraxin 3 and vitamin $\mathrm{D}$ receptor gene variants associate with pulmonary tuberculosis risk in West Africans. Genes Immun. 8, 456-467. doi:10.1038/sj.gene.6364410

Paroni, M., Moalli, F., Nebuloni, M., Pasqualini, F., Bonfield, T., Nonis, A., et al. (2012). Response of CFTRdeficient mice to long-term chronic Pseudomonas aeruginosa infection and PTX3 therapy. J. Infect. Dis. doi:10.1093/infdis/jis636

Pauwels, N. S., Bracke, K. R., Maes, T., Van Pottelberge, G. R., Garlanda, C., Mantovani, A., et al. (2010). Cigarette smoke induces PTX3 expression in pulmonary veins of mice in an IL-1 dependent manner. Respir. Res. 11, 134. doi:10.1186/1465-992111-134

Pepys, M. B., and Baltz, M. L. (1983). Acute phase proteins with special reference to C-reactive protein and related proteins (pentaxins) and serum amyloid A protein. Adv. Immunol. 34, 141-212. 
doi:10.1016/S0065-2776(08)60 379-X

Peri, G., Introna, M., Corradi, D., Iacuitti, G., Signorini, S., Avanzini, F., et al. (2000). PTX3, a prototypical long pentraxin, is an early indicator of acute myocardial infarction in humans. Circulation 102, 636-641. doi:10.1161/01.CIR.102.6.636

Planque, C., Kulasingam, V., Smith, C. R., Reckamp, K., Goodglick, L., and Diamandis, E. P. (2009). Identification of five candidate lung cancer biomarkers by proteomics analysis of conditioned media of four lung cancer cell lines. Mol. Cell. Proteomics 8, 2746-2758. doi:10.1074/mcp.M900134MCP200

Polentarutti, N., Bottazzi, B., Di Santo, E., Blasi, E., Agnello, D., Ghezzi, P., et al. (2000). Inducible expression of the long pentraxin PTX3 in the central nervous system. J. Neuroimmunol. 106, 87-94. doi:10.1016/S0165-5728(00)00 214-9

Presta, M., Camozzi, M., Salvatori, G., and Rusnati, M. (2007). Role of the soluble pattern recognition receptor PTX3 in vascular biology. J. Cell. Mol. Med. 11, 723-738. doi:10.1111/j.15824934.2007.00061.x

Ravizza, T., Moneta, D., Bottazzi, B., Peri, G., Garlanda, C., Hirsch, E., et al. (2001). Dynamic induction of the long pentraxin PTX3 in the CNS after limbic seizures: evidence for a protective role in seizure-induced neurodegeneration. Neuroscience 105, 43-53. doi:10.1016/S03064522(01)00177-4

Reading, P. C., Bozza, S., Gilbertson, B., Tate, M., Moretti, S., Job, E. R., et al. (2008). Antiviral activity of the long chain pentraxin PTX3 against influenza viruses. J. Immunol. 180, 3391-3398.

Rota, P. A., Oberste, M. S., Monroe, S. S., Nix, W. A., Campagnoli, R., Icenogle, J. P., et al. (2003). Characterization of a novel coronavirus associated with severe acute respiratory syndrome. Science 300 , 1394-1399.

doi:10.1126/science.1085952

Rusnati, M., Camozzi, M., Moroni, E., Bottazzi, B., Peri, G., Indraccolo, S., et al. (2004). Selective recognition of fibroblast growth factor2 by the long pentraxin PTX3 inhibits angiogenesis. Blood 104, 92-99.

Salustri, A., Garlanda, C., Hirsch, E., De Acetis, M., Maccagno, A., Bottazzi, B., et al. (2004). PTX3 plays a key role in the organization of the cumulus oophorus extracellular matrix and in in vivo fertilization. Development 131, 1577-1586. doi:10.1242/dev.01056
Soares, A. C., Souza, D. G., Pinho, V., Vieira, A. T., Nicoli, J. R., Cunha, F. Q., et al. (2006). Dual function of the long pentraxin PTX3 in resistance against pulmonary infection with Klebsiella pneumoniae in transgenic mice. Microbes Infect. 8, 1321-1329. doi:10.1016/j.micinf.2005.12.017

Suzuki, S., Shishido, T., Funayama, A., Netsu, S., Ishino, M., Kitahara, T., et al. (2003). Long pentraxin PTX3 exacerbates pressure overload-induced left ventricular dysfunction. PLoS ONE 8:e53133. doi:10.1371/journal.pone. 0053133

Van Pottelberge, G. R., Bracke, K. R., Pauwels, N. S., Vermassen, F. E., Joos, G. F., and Brusselle, G. G. (2012). COPD is associated with reduced pulmonary interstitial expression of pentraxin3. Eur. Respir. J. 39, 830-838. doi:10.1183/09031936.00138110

Vouret-Craviari, V., Matteucci, C., Peri, G., Poli, G., Introna, M., and Mantovani, A. (1997). Expression of a long pentraxin. Infect. Immun. 65, 1345-1350.

Wu, Q., Shu, H., Yao, S., and Xiang, H. (2009). Mechanical stretch induces pentraxin 3 release by alveolar epithelial cells in vitro. Med. Sci. Monit. 15, BR135-BR140.

Zhang, J., Shan, L., Koussih, L., Redhu, N. S., Halayko, A. J., Chakir, J., et al. (2012). Pentraxin 3 (PTX3) expression in allergic asthmatic airways: role in airway smooth muscle migration and chemokine production. PLoS ONE 7:e34965. doi:10.1371/journal.pone.003 4965

Conflict of Interest Statement: The authors declare that the research was conducted in the absence of any commercial or financial relationships that could be construed as a potential conflict of interest.

Received: 06 March 2013; accepted: 14 May 2013; published online: 31 May 2013.

Citation: Balhara J, Koussih L, Zhang $J$ and Gounni AS (2013) Pentraxin 3: an immuno-regulator in the lungs. Front. Immunol. 4:127. doi: 10.3389/fimmu.2013.00127

This article was submitted to Frontiers in Inflammation, a specialty of Frontiers in Immunology.

Copyright () 2013 Balhara, Koussih, Zhang and Gounni. This is an openaccess article distributed under the terms of the Creative Commons Attribution License, which permits use, distribution and reproduction in other forums, provided the original authors and source are credited and subject to any copyright notices concerning any third-party graphics etc. 